\title{
The Role of Autophagy in Stress and Cancer
}

\author{
Mehmet Bostanciklioglu* \\ Department of Physiology, Faculty of Medicine, Gaziantep University, Gaziantep, Turkey
}

\begin{abstract}
Programmed cell death plays an important role in development and disease. There are three main types of programmed cell death: apoptosis, autophagy, and necrosis. Apoptosis works on the two basic pathways called extrinsic and intrinsic; when there is a stress factor in a cell, apoptosis starts. Autophagy is critical for the continuation of normal human physiology such as the cellular homeostasis, energy balance, development and cellular defense. In addition to these, it may play a role in the pathogenesis of cancer, neurodegenerative diseases, aging, muscular diseases, infectious diseases, and immune system diseases.

While some autophagy genes showed tumor suppressive effect during the development of cancer, some other genes contributes to the survival of cancer cells during cancer progression. Therefore, the relationship between autophagy and cancer is quite complex. The role of autophagy in cancer varies depending on the stage of the cancer, the metabolic status of cell and the presence of stress. Also, it was reported that the expression of certain molecules associated with autophagy vary in different types of cancer. Autophagy is activated and allows the continuation of the viability of tumor cells in hypoxia. In case of nutrient deficiency, autophagy allows tumor tissue to gain time until nutrient, oxygen and growth factors become eligible again. Therefore, autophagy is seen as a necessary mechanism for tumor continuity. Autophagy increases both in cancer cells and normal cells during the cancer treatment. But, due to cancer cells use autophagy to survive more than normal cells; this case may generate new therapeutic opportunities. The studies needed to conduct to find new ways for using the genes play role in autophagy in cancer treatment.
\end{abstract}

In the present study, we aimed to throw light on the interaction of autophagy mechanism and some stresses such as ischemia and reperfusion and cancer development.

Keywords: Apoptosis; Autophagy; Necrosis; Cancer; Lysosomes

\section{Introduction}

\section{Autophagy mechanism}

Programmed cell death plays an important role in development and disease [1]. There are three main types of programmed cell death: apoptosis, autophagy, and necrosis. Apoptosis works on the two basic pathways called extrinsic and intrinsic; when there is a stress factor in a cell, apoptosis starts. When apoptosis starts, the cell digests itself via activation of pro-apoptotic genes in the $\mathrm{Bcl} 2$ gene family [2]. Unlike apoptosis, necrosis is a caspase-independent type of cell death. The most typical morphological feature of necrosis is the swelling of the cell and the emptying out of its contents. When necrosis occurs in the cells, inflammation is seen in that region [3]. The last type of programmed cell death is autophagy a physiologic phenomenon. Autophagy pathways are responsible for the digestion of durable proteins and cytoplasmic structures to provide energy, but this phenomenon is a targeted demolition rather than fragmentation [4]. Sometimes, autophagy can cause the cells to die on caspase-independent pathways in conditions in which apoptosis cannot function due to the disruption of apoptotic components [5]. This dual role of autophagy [6] still is not clear [7], but it is known that this mechanism is controlled by more than $30 \mathrm{Atg}$ (autophagy-related protein) genes [8]. The meaning of autophagy is self (auto) eating (phagy). Cells digest the parts of structures within the cell in order to obtain food under physiological conditions (hunger). Thus, intracellular molecules are recovered and homeostasis is maintained [9].

Autophagy is critical for the continuation of normal human physiology such as the cellular homeostasis, energy balance, development and cellular defense [10]. In addition to these, it may play a role in the pathogenesis of cancer, neurodegenerative diseases, aging, muscular diseases, infectious diseases, and immune system diseases $[11,12]$. Waste materials accumulated in the cell are broken through lysosomes containing acid hydrolase enzyme. Autophagy provides the removal of the damaged organelles and long-lasting cytoplasmic proteins through lysosomes [13]. Autophagy is a mechanism that contributes to homeostasis via the cycle of protein and organelle in cells under physiological conditions, and allows cell survival in the event of increased cellular stress [11]. Cancer and autophagy relationship is still controversial. While autophagy showed tumor suppressive effect during the development of cancer, it contributes to the survival of cancer cells during cancer progression [14].

Autophagy mechanism can be divided into five steps:

1. Starting, ATG/ULK (unc5- like kinase) component,

2. Nucleation, Beclin1/Class III PI3K (phosphatidylinositol-3 kinase) components,

3. Membrane elongation; two ubiquitin-like systems, ATG12 and ATG8/LC3

4. Collection, transmembrane protein (ATG9) and other ATG proteins for phagosome formation,

5. Mergers with lysosome and destruction: merge of auto

*Corresponding author: Mehmet Bostanciklioglu, Department of Physiology, Faculty of Medicine, Gaziantep University, Gaziantep, Turkey, Tel: +90342 360 12 00; E-mail: mehmet.bostanciklioglu27@gmail.com

Received May 06, 2015; Accepted May 12, 2015; Published May 15, 2015

Citation: Bostanciklioglu M (2015) HThe Role of Autophagy in Stress and Cancer. Single Cell Biol 4: 111. doi:10.4172/2168-9431.1000111

Copyright: (c) 2015 Bostanciklioglu M. This is an open-access article distributed under the terms of the Creative Commons Attribution License, which permits unrestricted use, distribution, and reproduction in any medium, provided the original author and source are credited. 
phagosome and lysosome, LAMP2 and RAB7 proteins, and lysosomal hydrolysis and degradation would eventually occur [15]. The stages of autophagy are shown in Figure 1 [16].

The most important stimulus in autophagy regulation is starvation, hypoxia and stress. TOR protein complex has an important role in the regulation of autophagy. Target of rapamycin (mTOR) is serine tyrosine kinases that control growth and protein synthesis in mammalian. Expression of mTOR plays role in cell growth, proliferation and survival. As well as it is also thought to be involved in uncontrolled growth of cancer cells.

Autophagy also provides the control of damaged intracellular organelles and proteins. Accumulation of damaged proteins and organelles may be toxic for cell is prevented due to autophagy. This is especially critical for cells, grow rapidly and have not appropriate blood flow due to metastasis. Autophagy disorders in tissues and tumor cause disrupted cellular stability, DNA damage, the mutation and genomic instability and ultimately contribute to tumor formation and progression [17]. These observations showed that stimulated autophagy may prevent the formation of cancer and autophagy mediated survival inhibition may suggest a new approach in the treatment of aggressive cancers. Despite recent advances in cancer treatment, chemotherapy and radiotherapy is unable to develop adequate response in many types of cancer and despite treatment, progression is recorded [18]. Autophagy is increased both in normal cells and cancer cells during cancer treatment. But, due to cancer cells use autophagy to survive more than normal cells; this case can generate new therapeutic opportunities [19].

Today, although the relationship between autophagy and cell death and survival is not fully understood, it is needed to say similar effects seen by cancer drugs. It was showed in vitro studies that chemotherapeutic agents increased auto phagosome formation in tumor cells [16]. For years, it was thought that these treatment lead cell to death by inducing autophagy, but now it has been observed that inhibition of autophagy leads to an increase in cell death rather than a decrease [16]. Therefore, it is thought that inhibition of autophagy is better rather than the induction of autophagy in cancer treatment. In a study conducted by Amaravadi et al. in 2007, it was showed that chloroquine disrupts the autophagy degradation in mice with c-Myc-related lymphoma increase the death of the tumor cells by enhancing the effect of DNA alkylating agents and provides tumor regression [20]. However, it is difficult to say that the effects of chloroquine develop as a result of autophagy inhibition because it has impact on both multidrug pump and host immune system cells [21]. In the future, the work will be done with the use of autophagy-specific inhibitory agent may be answer to these questions. The role of autophagy in cancer probably varies according to tumor progression. The inhibition of autophagy in precancerous cells can lead to sustained growth and in this case autophagy acts as a tumor suppressor. Later, when the tumor grow enough, cancer cells need to autophagy to survival in poor conditions without food and oxygen, this may be particularly significant in the less vascularized internal parts of tumor [22].

In recent studies, it was showed that Atg14L integrated into Beclin1, thought to be tumor suppressor, and had an important role in the formation of auto phagosome. Beclin1 is reduced by siRNAs. It was showed that Atg14L plays an active role in the regulation of P13K-Ш other tumor suppressor gene [23]. There is no information about Atg14L play what kind of role in a cancer. The studies include plenty of samples are needed to conduct to show the role of Atg14L in cancer.

\section{Autophagy and basal cell carcinoma}

Skin cancer is one of the most common cancers in the world. 700,000 new cases per year are faced [24]. Skin cancers are divided into melanoma and non-melanoma cancer. Non-melanoma skin cancer is the most common type of skin cancer in the world. $77 \%$ of skin cancer is basal cell carcinoma (BCC), $20 \%$ of is squamous cell carcinoma (SCC), and melanoma and other rare skin cancers include remaining $3 \%$ [25]. Malignant tumors of the epidermis containing BCC and SCC constituting about $90 \%$ of all cutaneous malignancies [26-29].

Basal cell carcinoma (BCC) is a malignant neoplasm emerging from the basal cells of the epidermis [30]. The lesion showing slow destruction and has hard eradication was called as "rodent ulcer" for the first time in Dublin in 1827 by the researcher named Jacob. Basal cell carcinoma was first described in 1903 by Krompecher [31]. It is often seen in chronically sun-exposed areas of individuals. BCCs are dependent on the stroma and this stromal addiction is the cause of

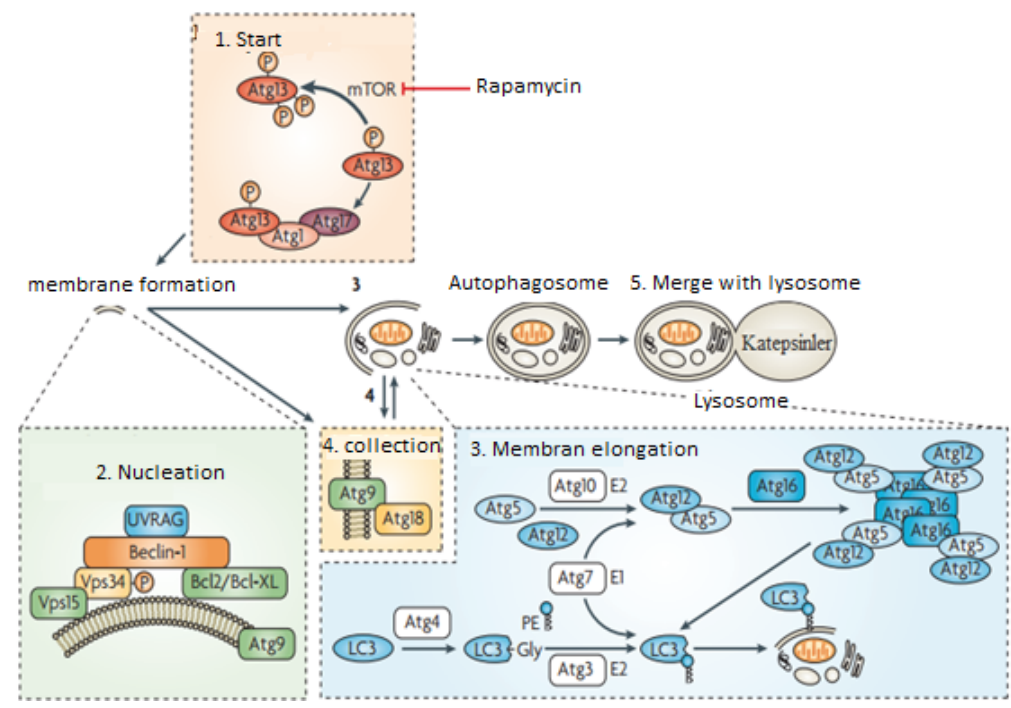

Figure 1: Autophagy stages. 
metastasis of these tumors (metastasis incidence of 0.1\%) [32]. Despite the low mortality rate, these tumors constitute an important public health problem compared to the others [33].

It is more common in men than in women (1.5-2 times) [34]. BCC incidence is increasing $10 \%$ annually since the year 60 s all over the world [35]. The worldwide incidence of BCC is estimated to increase by $20-80 \%$ in last thirty years [36]. The incidence in young and middleaged people under 50 years of age is increasing. Especially in young women ( $<40$ years), a severe increase in BCC incidence is observed due to the increased exposure of natural or artificial UV rays for tanning [34]. BCC 10-16 times more common in patient's organ transplanted [35]. BCC can be encountered anywhere in the body, but it is most commonly seen on head and neck (80\%) [35].

Although BCC has usually the best skin cancer prognosis, when it is untreated, it makes local invasion and may invade until subcutaneous tissue, muscle and even bone [37]. Distant metastases are rare (\%0, 0028-0, 55) [34]. After under treatment, 33\% recurrences are seen in the first year, it will be $50 \%$ in the first 2 years, will be $66 \%$ in the first 3 years and will be $18 \%$ between $5-10$ years $[38,39]$. The emergence rate of the tumor doubling is about between 6 months -1 year. After BCC treatment, a second BCC may develop in $44 \%$ of patients in 3 years [38].

While primary BCC is seen by $86 \%$ in head and neck region, this ratio is about $7 \%$ in the trunk and extremities. The most frequent locations in the head and neck; nose (25.5\%), cheeks (16\%), periorbital area (14\%), scalp (11\%), preauricular area (11\%) [37]. In $40 \%$ of patients basal cell carcinoma detected, one or more BCC development is expected [40].

There are 5 main clinical types of BCC's. These are superficial BCC, pigmented BCC, morphea-like BCC, fibroepithelioma and sclerosant BCC [37].

Basal cell carcinomas are not metastasizing. However, there are exceptions [32]. While the incidence of metastases is $0.01 \%$ in pathological specimens, it is $0.028 \%$ in dermatological patients and reaches to $0.1 \%$ in patients in surgical centers [41]. This is associated with stromal dependencies of BCC. There is a relationship between tumor size and metastasis in BCC. When tumor diameter is $3 \mathrm{~cm}$, while the rate is increased by $1-2 \%$, when the diameter is $5-10 \mathrm{~cm}$, this rate reaches to $20-25 \%$. There is $50 \%$ increase, greater than $10 \mathrm{~cm}$, in metastasis of tumors [42]. Places occurred BCC metastasis are lymph node (40-80\%), lung (35-53\%), bone (20-80\%), skin (10-17\%), liver (9\%) [43].

Although five-year recurrence rate varies depending on treatment way, it is approximately $5 \%$ [44]. In long-term follow-up, this proportion rises to $9 \%$ [45]. While following the initial surgical procedure majority of recurrence was seen in three years, about 20\% appears 6-10 years later after surgery [42].

Monoallelic deletion of UVRAG gene was frequently found in human colon cancer, UVRAG is involved in the inhibition of proliferation and tumorigenesis [46].

Death associated protein kinase 1 (DAPK1) has an important role in cell death and regulation of autophagy. It is known that DAPK1 has tumor suppressor role [47]. When the expression of DAPK1 increased in cell, the numbers of LCШ, markers of autophagy, increased was observed. DAPK1 were actually identified as activators of IFNG $[47,48]$.

IFNG regulates the expression of DAPK1. DAPK a serine/threonine kinase and regulated by binding of calcium/ calmodulin regulates both apoptosis and autophagy via at least two ways. The oncogenes require
DAPK protein for p53 activation and stimulation of apoptosis [49]. It is also required in apoptotic cell death induced by TGF-b in liver cancer cells [50]. Besides, DAPK plays a role in the autophagy cell death induced by IFN- $\gamma$ [51]. In the absence of amino acid, it was suggested that microtubule-binding protein (MAP1B) is important in the stimulation of autophagy by DAPK [51-53]. Interestingly, it was claimed to activate mTOR by phosphorylating Tsc2, a regulator of mTOR, and inhibit autophagy [54]. The number of publications about high expression DAPK activates autophagy is greater than the publications related suppression of autophagy. The most convincing molecular explanation how DAPK activate autophagy is associated with Beclin1. DAPK is directly connected Beclin and phosphorylates it. Beclin1' BH3 region serve to connect to $\mathrm{Bcl}-2$ family proteins, phosphorylation target of DAPK. After phosphorylation, Beclin1 separates from Bcl-xL and is capable of taking part in the activation of autophagy [55]. Gozuacik and Kimchi' group have observed that DAPK 1 plays a role in the induction of both apoptosis and autophagy even in the same cell. Endoplasmic reticulum (ER) stress stimulates both autophagy and apoptosis (caspase activation) in fibroblasts and both pathways contributes to cell death. It was observed that cells obtained from mouse and organ such as kidney were protected from cell death caused by ER stress [54,56]. These works showed that DAPK plays an important role in cell death caused by activation of autophagy and apoptosis and underlined that DAPK could play a molecular switch role between two cell death types [56,57].

Furthermore, it was showed that activated autophagy caused death in the T cells lacking of FADD and caspase- 8 activity [58]. In this autophagy signal, it is argued that FADD formed a complex with Atg5-Atg12/RIPK1 and then this complex forefoot to connection of caspase-8. In addition, it was observed that when ATG7 or autophagy signal was blocked by chemical agents, the proliferation of $\mathrm{T}$ cells was re-occurred due to the caspase- 8 inhibition increased autophagy [22]. All of these findings suggest that relationship between autophagy and apoptosis affects decision on the survival of cells.

EIF2AK3 triggers autophagy mechanism by creating stress in the endoplasmic reticulum (ER). It decreases apoptosis when autophagy is increased. ATF6, ERN1, EIF2AK3 are ER stress sensors located on ER membrane. When these are increased, the protein folding capacity increase in ER and protein installation work on ER is reduced. Increased ER stress triggers autophagy.

When EIF2AK3 silenced, apoptosis increases in breast cancer cell lines. EIF2AK3 increases apoptosis in breast cancer through siRNA. This gene is said to have pro-survivor effect. So it has anti-apoptotic effect [59].

TMEM74 gene localized on lysosomes and auto phagosome increases autophagy vacuolization and promotes autophagy in cellular starvation and stress conditions [60]. In the literature, there is no cancer related to increased TMEM74 gene expression. $66.6 \%$ increase was recorded in the present study.

GABARAPL-1 is a protein has important intracellular transport functions. There are studies suggesting that GABARAP and GABARAPL-1 related tumor growth. In studies performed on patients with breast cancer, GABARAPL-1 mRNA level was found lower in the patients with high histological grade, lymph node metastasis and hormone receptor negative. GABARAPL-1 mRNA level is a good indicator in determining of recurrence and lymph node metastasis in breast cancer [61,62].

IRG family stimulator of interferon contains 20 proteins in mice. Many of these are required for IFN- $\gamma$ develop resistance to intracellular 
pathogens [63]. There are 2 units of this family in people. These are: IRGM and IRGC limited to testicular. IRGM plays a role in the destruction of mycobacterium bovis via an autophagy mediated way [64], and is one of the genes increase autophagy mechanisms. Its expression is said to be associated with Crohn's disease [65]. There are publications associated with colorectal cancer [66]. 52.3\% increase was recorded in the present study.

The expression of some genes play role in autophagy may increase or decrease in cancer. Therefore, autophagy mechanism is an effective mechanism on cancer and the relationship with cancer is quite complex. While some of these acts as oncogenes, some act as tumor suppressor genes.

\section{Autophagy and ischemia/ reperfusion}

Ischemia is described that the tissue requirements, like oxygen and other metabolites cannot be provided by circulating system or cannot be removed of wastes from cells [67]. I/R not only cause damage in the tissue but also induce some pathology including lipid peroxidation, edema, apoptosis and acute inflammatory reactions [68]. There are more factors affect the mechanism underlying of $I / R$ injury [69]. Until recently, mitochondria has been regarded as a plant for energy protection, but now it is known to play important roles to decide whether cell is going to death in the condition of I/R injury [70,71].

In I/R models, ROS is the most important contributors to cell death during the reperfusion [72]. ROS is produced by both molecular oxygen entered to cell during reperfusion [73] and released by mitochondria in the case of stress [74].

ROS is in close connection with autophagy mechanism and increased ROS produced by oxidative stress specially in the reperfusion stage of ischemia/reperfusion induces autophagy was shown by Zeng et al. [75], consistent with these result, Wang et al. [76] have reported that 2-Deoxy-D-glucose treatment starts autophagy by causing excessive ROS in the cell via [ROS- AMP- protein kinase (AMPK)autophagy] pathway. Wang et al. [77] in their study, shown reperfusion caused strong autophagy response in hepatocytes. In addition to these studies, Zhang et al. [78], indicated intracellular ROS may leads cells to apoptosis or autophagy via PI3K/AKT/mTOR/ P70S6K and JNK signal pathways, and when $\mathrm{H} 2 \mathrm{O} 2$ treatment is applied to human umbilical vein endothelial cells (HUVECs), Beclin1 and p65 expressions increase [75], also when BHA and NAC which are scavengers of ROS are added to the medium, autophagy is inhibited by decreasing of expression of p65 and Beclin1 was shown [75].

Contrary to these data, Fan et al. [72] think that autophagy is not maintained during reperfusion, instead of this, this mechanism can work as a protective mechanism against to ischemia, consistently with Fan et al'data, recent studies have shown that ROS may use caspase dependent apoptosis pathways to bring cell to death [79] and caspase -3 cleaves some autophagic genes (Atg3, Beclin1 and Atg4) [80].

In addition to ROS, the other important factor can cause strong autophagic response during ischemia is starvation [81]. Due to the fact that the main task of autophagy known is to provide energy to cells, it is accepted that starvation is the most powerful spark ignites this mechanism.

One of the important factors affects autophagic response is duration of I and R. Zuo et al. [74] shown that activity of autophagy increases as long as period of ischemia and reperfusion strings out. Atg10 is activated form of Atg12, beside of this, is another ubiquitin-conjugating enzyme and provides conjugation of Atg12 and Atg5 [82,83]. In conclusion, increased Atg10 expression's mean is activated autophagy mechanism. Also, Li et al. [84] presented that acute (3h) ischemia in the barrel cortex is enough to start nuclear condensation and increase Beclin1 expression. Beclin1 reached top level 12 to $24 \mathrm{~h}$ after ischemia [84]. Due to the fact that it is widely believed the securest marker of autophagy is the ratio of LC3-II/LC3-I, Li et al. [84] not only shown the increase of expression of Beclin1 but also showed the ratio of LC3-II/ LC3-I to verify their results.

As for the function of autophagy in $\mathrm{I} / \mathrm{R}$, a growing body of evidence indicates that autophagy, triggered by ischemia may, leads cells to death, especially in the brain [84-88]. However, this depend on cell type and duration of $\mathrm{I} / \mathrm{R}$ as there are a great number of studies shown autophagy works to keep cells safe from death [89].

\section{Conclusions}

Autophagy increases both in cancer cells and normal cells during the cancer treatment. But, due to cancer cells use autophagy to survive more than normal cells; this case may generate new therapeutic opportunities. Normally, while the expressions of therapeutic genes increase to ensure intracellular homeostasis, but in some stress condition and cancer status decreased therapeutic autophagy gene expressions to insulate cells from cytotoxicity indicates areas for further study of the interaction mechanism between autophagy, ischemia/ reperfusion and cancer.

\section{References}

1. Simsek F, Patriot HS (2014) A new type of organization apoptotic and autophagic death in intracellular magazine 31: 6-11.

2. Arden N, Betenbaugh MJ (2006) Regulating apoptosis in mammalian cell cultures. Cytotechnology 50: 77-92.

3. Los M, Mozoluk M, Ferrari D, Stepczynska A, Stroh C, et al. (2002) Activation and caspase-mediated inhibition of PARP: a molecular switch between fibroblast necrosis and apoptosis in death receptor signaling. Mol Biol Cell 13 978-988.

4. Hands SL, Proud CG, Wyttenbach A (2009) mTOR's role in ageing: protein synthesis or autophagy? Aging (Albany NY) 1: 586-597.

5. Self Arslan GK revolution, revolution Gozuacik (2011) Autophagy: a cellular stress response and Death Mechanism. Acibadem University Journal of Medical Sciences.

6. Galluzzi L, Maiuri MC, Vitale I, Zischka H, Castedo M, et al. (2007) Cell death modalities: classification and pathophysiological implications. Cell Death Differ 14: $1237-1243$.

7. Jain MV, Paczulla AM, Klonisch T, Dimgba FN, Rao SB, et al. (2013) Interconnections between apoptotic, autophagic and necrotic pathways: implications for cancer therapy development. J Cell Mol Med 17: 12-29.

8. Xie Z, Klionsky DJ (2007) Autophagosome formation: core machinery and adaptations. Nat Cell Biol 9: 1102-1109.

9. Ohsumi Y (2001) Molecular dissection of autophagy: two ubiquitin-like systems Nat Rev Mol Cell Biol 2: 211-216.

10. Kroemer G, Marino G, Levine B (2010) Autophagy and the integrated stress response. Mol Cell 40: 280-293.

11. Levine B, Kroemer G (2008) Autophagy in the pathogenesis of disease. Cell 132: $27-42$.

12. Betin VM, Lane JD (2009) Caspase cleavage of Atg4D stimulates GABARAP-L1 processing and triggers mitochondrial targeting and apoptosis. J Cell Sci 122 2554-2566.

13. Klionsky DJ, Emr SD (2000) Autophagy as a regulated pathway of cellular degradation. Science 290: 1717-1721.

14. Rouschop KM, Wouters BG (2009) Regulation of autophagy through multiple independent hypoxic signaling pathways. Curr Mol Med 9: 417-424.

15. Frankel LB, Lund AH (2012) MicroRNA regulation of autophagy. Carcinogenesis 33: $2018-2025$. 
16. Maiuri MC, Zalckvar E, Kimchi A, Kroemer G (2007) Self-eating and self-killing: crosstalk between autophagy and apoptosis. Nat Rev Mol Cell Biol 8: 741-752.

17. Karantza-Wadsworth V, Patel S, Kravchuk O, Chen G, Mathew R, et al. (2007) Autophagy mitigates metabolic stress and genome damage in mammary tumorigenesis. Genes Dev 21: 1621-1635.

18. Chen S, Rehman SK, Zhang W, Wen A, Yao L, et al. (2010) Autophagy is a therapeutic target in anticancer drug resistance. Biochim Biophys Acta 1806: 220-229

19. White E, DiPaola RS (2009) The double-edged sword of autophagy modulation in cancer. Clin Cancer Res 15: 5308-5316.

20. Amaravadi RK, Yu D, Lum JJ, Bui T, Christophorou MA, et al. (2007) Autophagy inhibition enhances therapy-induced apoptosis in a Myc-induced model of lymphoma. J Clin Invest 117: 326-336.

21. Apetoh L, Ghiringhelli F, Tesniere A, Obeid M, Ortiz C, et al. (2007) Tolllike receptor 4-dependent contribution of the immune system to anticancer chemotherapy and radiotherapy. Nat Med 13: 1050-1059.

22. Cuervo AM (2004) Autophagy: in sickness and in health. Trends Cell Biol 14 70-77.

23. Thoresen SB, Pedersen NM, LiestølK, Stenmark H (2010)A phosphatidylinosito 3-kinase class III sub-complex containing VPS15, VPS34, Beclin, UVRAG and BIF-1 regulates cytokinesis and degradative endocytic traffic. Exp Cell Res 316: 3368-3378.

24. Hussain M, Earley MJ (2003) The incidence of incomplete excision in surgically treated basal cell carcinoma: a retrospective clinical audit. Ir Med J 96: 18-20.

25. Auepemkiate S, Boonyaphiphat $P$, Thongsuksai $P$ (2002) p53 expression related to the aggressive infiltrative histopathological feature of basal cell carcinoma. Histopathology 40: 568-573.

26. Bolshakov S, Walker CM, Strom SS, Selvan MS, Clayman GL, et al. (2003) p53 mutations in human aggressive and nonaggressive basal and squamous cell carcinomas. Clin Cancer Res 9: 228-234.

27. Dicker T, Siller G, Saunders N (2002) Molecular and cellular biology of basal cell carcinoma. Australas J Dermatol 43: 241-246.

28. LeBoit PE, Burg G, Weedon D, Sarasin A (2006) Keratinocytic tumours, World Health Organization Classification of Tumours, Pathology and Genetics of Skin Tumours. 9-47.

29. D. W (2002) Tumors of the epidermis. Skin Pathology. Churchill Livingstone, China 2: 753-802.

30. Bagheri MM, Safai B (2001) Cutaneous malignancies of keratinocytic origin. Clin Dermatol 19: 244-252

31. Puizina-Ivić N, Matoković B, Gluncić I, Maslovara S, Vela-Ljubić J (1999) Histopathologic variants of basal cell carcinoma correlation with sex, age and localization. J Med Syst 23: 389-400.

32. Anjaneyulu A, Reddy VK, Raju PK, Rajagopalaraju A, Kumar AS, et al. (2001) Acute reversible left ventricular dysfunction following general anesthesia. Indian Heart J 53: 508-510.

33. Miller DL, Weinstock MA (1994) Nonmelanoma skin cancer in the United States: incidence. J Am Acad Dermatol 30: 774-778.

34. Carucci JA LD (2008) Basal cell carcinoma, Fitzpatrick's Dermatology in General Medicine. 1036-1042.

35. Madan V, Lear JT, Szeimies RM (2010) Non-melanoma skin cancer. Lancet 375: 673-685.

36. LeBoit PE BG, Sarasin A, Weedon D (2006). World Health Organization Classification of Tumours. Pathology and Genetics of Skin Tumours.

37. Netscher DT SM (2004) Basal cell carcinoma: An overview of tumor biology and treatment. Plast Reconstr Surg 113: 74-94.

38. Walker P HD (2006) Surgical treatment of basal cell carcinomas using standard postoperative histological assessment. Australas J Dermatol 47: 1-12.

39. Mak SY KK, Tung MK (1994) Management of basal cell carcinoma and local experience. HK Pract 16: 484-487.

40. Zagrodnik B, Kempf W, Seifert B, Müller B, Burg G, et al. (2003) Superficial radiotherapy for patients with basal cell carcinoma: recurrence rates, histologic subtypes, and expression of p53 and Bcl-2. Cancer 98: 2708-2714.
41. Elder DE, Elenitsas R, Johnson BLJr, Murphy GF (2005) Histology of the skin Lever's Histopathology of the Skin, IX. Baski, Philadelphia, W.W. Lippincott. 10-58.

42. Crowson AN (2006) Basal cell carcinoma: biology, morphology and clinical implications. Mod Pathol 19 Suppl 2: S127-147.

43. Rowe DE, Carroll RJ, Day CL Jr (1989) Long-term recurrence rates in previously untreated (primary) basal cell carcinoma: implications for patient follow-up. J Dermatol Surg Oncol 15: 315-328.

44. Allam JP, Novak N, Fuchs C, Asen S, Bergé S, et al. (2003) Characterization of dendritic cells from human oral mucosa: a new Langerhans' cell type with high constitutive FcepsilonRI expression. J Allergy Clin Immunol 112: 141-148.

45. Ramachandran S, Fryer AA, Smith AG, Lear JT, Bowers B, et al. (2000) Basal cell carcinoma. Cancer 89: 1012-1018.

46. Liang C, Feng P, Ku B, Dotan I, Canaani D, et al. (2006) Autophagic and tumour suppressor activity of a novel Beclin1-binding protein UVRAG. Nat Cell Biol 8 : 688-699.

47. Gade P, Manjegowda SB, Nallar SC, Maachani UB, Cross AS, et al. (2014) Regulation of the death-associated protein kinase 1 expression and autophagy via ATF6 requires apoptosis signal-regulating kinase 1. Mol Cell Biol 34: 40334048

48. Kalvakolanu DV, Gade P (2012) IFNG and autophagy: a critical role for the ER-stress mediator ATF6 in controlling bacterial infections. Autophagy 8: 16731674.

49. Raveh T, Droguett G, Horwitz MS, DePinho RA, Kimchi A (2001) DAP kinase activates a p19ARF/p53-mediated apoptotic checkpoint to suppress oncogenic transformation. Nat Cell Biol 3: 1-7.

50. Jang CW, Chen CH, Chen CC, Chen JY, Su YH, et al. (2002) TGF-beta induces apoptosis through Smad-mediated expression of DAP-kinase. Nat Cell Biol 4 51-58.

51. Bialik S, Kimchi A (2006) The death-associated protein kinases: structure, function, and beyond. Annu Rev Biochem 75: 189-210.

52. Harrison B, Kraus M, Burch L, Stevens C, Craig A, et al. (2008) DAPK-1 binding to a linear peptide motif in MAP1B stimulates autophagy and membrane blebbing. J Biol Chem 283: 9999-10014.

53. Halpain S, Dehmelt L (2006) The MAP1 family of microtubule-associated proteins. Genome Biol 7: 224

54. Stevens C LY, Harrison B, Burch L, Ridgway RA, Sansom O, Hupp T. (2009) Peptide combinatorial libraries identify TSC2 as a death-associated protein kinase (DAPK) death domain-binding protein and reveal a stimulatory role for DAPK in mTORC1 signaling. J Biol Chem 284: 334-344.

55. Zalckvar E, Berissi H, Mizrachy L, Idelchuk Y, Koren I, et al. (2009) DAP-kinasemediated phosphorylation on the $\mathrm{BH} 3$ domain of beclin 1 promotes dissociation of beclin 1 from Bcl-XL and induction of autophagy. EMBO Rep 10: 285-292.

56. Gozuacik D, Bialik S, Raveh T, Mitou G, Shohat G, et al. (2008) DAP-kinase is a mediator of endoplasmic reticulum stress-induced caspase activation and autophagic cell death. Cell Death Differ 15: 1875-1886.

57. Eisenberg-Lerner A, Bialik S, Simon HU, Kimchi A (2009) Life and death partners: apoptosis, autophagy and the cross-talk between them. Cell Death Differ 16: 966-975.

58. Bell BD, Leverrier S, Weist BM, Newton RH, Arechiga AF, et al. (2008) FADD and caspase- 8 control the outcome of autophagic signaling in proliferating $T$ cells. Proc Natl Acad Sci U S A 105: 16677-16682.

59. Zhao C, Yin S, Dong Y, Guo X, Fan L, et al. (2013) Autophagy-dependent EIF2AK3 activation compromises ursolic acid-induced apoptosis through upregulation of MCL1 in MCF-7 human breast cancer cells. Autophagy 9: 196-207.

60. Cho DH, Jo YK, Hwang JJ, Lee YM, Roh SA, et al. (2009) Caspase-mediated cleavage of ATG6/Beclin-1 links apoptosis to autophagy in HeLa cells. Cancer Lett 274: 95-100.

61. Guo GF, Jiang WQ, Zhang B, Cai YC, Xu RH, et al. (2011) Autophagy-related proteins Beclin-1 and LC3 predict cetuximab efficacy in advanced colorectal cancer. World J Gastroenterol 17: 4779-4786.

62. Berthier A, Seguin S, Sasco AJ, Bobin JY, De Laroche G, et al. (2010) High expression of gabarapl1 is associated with a better outcome for patients with lymph node-positive breast cancer. Br J Cancer 102: 1024-1031. 
63. Henry SC, Daniell X, Indaram M, Whitesides JF, Sempowski GD, et al. (2007) Impaired macrophage function underscores susceptibility to Salmonella in mice lacking Irgm1 (LRG-47). J Immunol 179: 6963-6972.

64. Gutierrez MG, Master SS, Singh SB, Taylor GA, Colombo MI, et al. (2004) Autophagy is a defense mechanism inhibiting BCG and Mycobacterium tuberculosis survival in infected macrophages. Cell 119: 753-766.

65. Rioux JD, Xavier RJ, Taylor KD, Silverberg MS, Goyette P, et al. (2007) Genome-wide association study identifies new susceptibility loci for Crohn disease and implicates autophagy in disease pathogenesis. Nat Genet 39: 596-604.

66. Brest P, Corcelle EA, Cesaro A, Chargui A, Belaïd A, et al. (2010) Autophagy and Crohn's disease: at the crossroads of infection, inflammation, immunity, and cancer. Curr Mol Med 10: 486-502.

67. Orrenius S, Burkitt MJ, Kass GE, Dypbukt JM, Nicotera P (1992) Calcium ions and oxidative cell injury. Ann Neurol 32 Suppl: S33-42.

68. Elsegood CL, Chang M, Jessup W, Scholz GM, Hamilton JA (2009) Glucose metabolism is required for oxidized LDL-induced macrophage survival: role of $\mathrm{PI} 3 \mathrm{~K}$ and Bcl-2 family proteins. Arterioscler Thromb Vasc Biol 29: 1283-1289.

69. Jaeschke H, Lemasters JJ (2003) Apoptosis versus oncotic necrosis in hepatic ischemia/reperfusion injury. Gastroenterology 125: 1246-1257.

70. Hagberg $\mathrm{H}$ (2004) Mitochondrial impairment in the developing brain after hypoxia-ischemia. J Bioenerg Biomembr 36: 369-373.

71. Sas K, Robotka H, Toldi J, Vécsei L (2007) Mitochondria, metabolic disturbances, oxidative stress and the kynurenine system, with focus on neurodegenerative disorders. J Neurol Sci 257: 221-239.

72. Fan J, Zhang Z, Chao X, et al. (2014) Ischemic preconditioning enhances autophagy but suppresses autophagic cell death in rat spinal neurons following ischemia-reperfusion. Brain Res 1562: 76-86.

73. Phillips L, Toledo AH, Lopez-Neblina F, Anaya-Prado R, Toledo-Pereyra LH (2009) Nitric oxide mechanism of protection in ischemia and reperfusion injury. $\mathrm{J}$ Invest Surg 22: 46-55.

74. Zuo W, Zhang S, Xia CY, Guo XF, He WB, et al. (2014) Mitochondria autophagy is induced after hypoxic/ischemic stress in a Drp1 dependent manner: the role of inhibition of Drp1 in ischemic brain damage. Neuropharmacology 86: 103-115.

75. Zeng M, Wei X, Wu Z, Li W, Li B, et al. (2014) Reactive oxygen species contribute to simulated ischemia/reperfusion-induced autophagic cell death in human umbilical vein endothelial cells. Med Sci Monit 20: 1017-1023.

76. Wang Q, Liang B, Shirwany NA, Zou MH (2011) 2-Deoxy-D-glucose treatment of endothelial cells induces autophagy by reactive oxygen species-mediated activation of the AMP-activated protein kinase. PLoS One 6:e17234.
77. Wang JH, Ahn IS, Fischer TD, Byeon JI, Dunn WA Jr, et al. (2011) Autophagy suppresses age-dependent ischemia and reperfusion injury in livers of mice. Gastroenterology 141: 2188-2199.

78. Zhang L, Wang H, Xu J, Zhu J, Ding K (2014) Inhibition of cathepsin S induces autophagy and apoptosis in human glioblastoma cell lines through ROSmediated PI3K/AKT/mTOR/p70S6K and JNK signaling pathways. Toxicol Lett 228: $248-259$.

79. Cheng WW, Lin ZQ, Wei BF, Zeng Q, Han B, et al. (2011) Single-walled carbon nanotube induction of rat aortic endothelial cell apoptosis: Reactive oxygen species are involved in the mitochondrial pathway. Int J Biochem Cell Biol 43: 564-572.

80. Norman JM, Cohen GM, Bampton ET (2010) The in vitro cleavage of the hAtg proteins by cell death proteases. Autophagy 6: 1042-1056.

81. Nagelkerke A, Bussink J, Geurts-Moespot A, Sweep FC, Span PN (2015) Therapeutic targeting of autophagy in cancer. Part II: pharmacological modulation of treatment-induced autophagy. Semin Cancer Biol 31: 99-105.

82. Kim J, Dalton VM, Eggerton KP, Scott SV, Klionsky DJ (1999) Apg7p/Cvt2p is required for the cytoplasm-to-vacuole targeting, macroautophagy, and peroxisome degradation pathways. Mol Biol Cell 10: 1337-1351.

83. Shintani T, Mizushima N, Ogawa Y, Matsuura A, Noda T, et al. (1999) Apg10p, a novel protein-conjugating enzyme essential for autophagy in yeast. EMBO J 18: $5234-5241$.

84. Li WL, Yu SP, Chen D, Yu SS, Jiang YJ, et al. (2013) The regulatory role of NF-kB in autophagy-like cell death after focal cerebral ischemia in mice. Neuroscience 244: 16-30.

85. Choi KE, Hall CL, Sun JM, Wei L, Mohamad O, et al. (2012) A novel stroke therapy of pharmacologically induced hypothermia after focal cerebral ischemia in mice. FASEB J 26: 2799-2810.

86. Tian F, Deguchi K, Yamashita T, Ohta Y, Morimoto N, et al. (2010) In vivo imaging of autophagy in a mouse stroke model. Autophagy 6: 1107-1114.

87. Rami A, Langhagen A, Steiger S (2008) Focal cerebral ischemia induces upregulation of Beclin 1 and autophagy-like cell death. Neurobiol Dis 29: 132-141.

88. Adhami F, Liao G, Morozov YM, Schloemer A, Schmithorst VJ, et al. (2006) Cerebral ischemia-hypoxia induces intravascular coagulation and autophagy. Am J Pathol 169: 566-583.

89. Kim JS, Nitta T, Mohuczy D, O’Malley KA, Moldawer LL, et al. (2008) Impaired autophagy: A mechanism of mitochondrial dysfunction in anoxic rat hepatocytes. Hepatology 47: 1725-1736. 